\title{
Cerrorchestia taboukeli sp. nov., a new terrestrial amphipod (Amphipoda, Talitridae) from Martinique Island
}

\author{
Christophe PISCART ${ }^{1, *}$, Khaoula AYATI ${ }^{2} \&$ Mathieu COULIS ${ }^{3}$ \\ ${ }^{1}$ Univ Rennes, CNRS, ECOBIO - UMR 6553, F-35000, Rennes, France. \\ ${ }^{2}$ Université de Carthage, Faculté des Sciences de Bizerte, \\ LR01ES14 Bio Surveillance de l'Environnement, 7021, Bizerte, Tunisia. \\ ${ }^{3}$ CIRAD, UPR GECO, F-97285 Le Lamentin, Martinique, France. \\ *Corresponding author: christophe.piscart@univ-rennes1.fr \\ 2Email: ayatikhaoula@gmail.com \\ 2Email: mathieu.coulis@cirad.fr \\ ${ }^{1}$ urn:1sid:zoobank.org:author:E652BD99-AA01-44BC-8DAC-EB8B3D290233 \\ ${ }^{2}$ urn:lsid:zoobank.org:author:62F7C68C-FCDF-4351-8DAD-B1858F4B77FE \\ ${ }^{3}$ urn:lsid:zoobank.org:author:5B4D4D04-5D8A-47B7-BB82-6B856C6B9EF6
}

\begin{abstract}
During recent investigations on the terrestrial invertebrates of the tropical rainforest on Martinique Island (Pitons du Carbet), specimens of a new species of the terrestrial amphipod genus Cerrorchestia Lindeman, 1990, C. taboukeli sp. nov., were collected by means of different quantitative and non-quantitative methods (hand collection and Tullgren extraction) in the forest floor. The new species can be easily distinguished from the only other species of the genus, $C$. hyloraina Lindeman, 1990, by gnathopod 2 (carpus short, palm longer than wide), pereopod 4 dactylus with a denticulate patch, pereopod 5 basis ovate with a deep posterodistal lobe reaching the distal end of the ischium, pleopod 3 ramus with more than six articles. Cerrorchestia tabouleki sp. nov. is the first forest-hopper discovered in the Lesser Antilles, raising the question of island colonization by terrestrial amphipods. Ecological data and a key to terrestrial Talitridae of Central America and the Caribbean islands are provided.
\end{abstract}

Keywords. Caribbean island, Lesser Antilles, tropical rainforest, terrestrial crustacean, new species.

Piscart C., Ayati K. \& Coulis M. 2019. Cerrorchestia taboukeli sp. nov., a new terrestrial amphipod (Amphipoda, Talitridae) from Martinique Island. European Journal of Taxonomy 588: 1-14. https://doi.org/10.5852/ejt.2019.588

\section{Introduction}

The Caribbean Region is inhabited by 21 terrestrial or semi-terrestrial species belonging to the Talitridae family (Bousfield 1984; Lindeman 1990; Smith 1998; Smith \& Heard 2001; Ortiz \& Lalana 2009; Wildish \& LeCroy 2014). These species belong to ten genera (Cariborchestia Smith, 1998, Caribitroides Bousfield, 1984, Cerrorchestia Lindeman, 1990, Chelorchestia Bousfield, 1984, Floreorchestia Bousfield, 1984, Mexitroides Lindeman, 1990, Mexorchestia Wildish \& LeCroy, 2014, Platorchestia 
Bousfield, 1982, Talitroides Bonnier, 1898, Talorchestia Dana, 1852) and could be pooled into three different ecological groups (i.e., beach-hoppers, field-hoppers and forest-hoppers) according to their environmental distribution and morphological adaptations (Lowry \& Myers 2019). Almost half of the Caribbean species belong to beach-hopper and field-hopper groups of species (Bousfield 1984; Ciavatti 1989) and 11 species could be considered as forest-hoppers (i.e., terrestrial species), which are known to inhabit the rain and cloud forests of the Greater Antilles islands and Central America (Lindeman 1990, Ortiz \& Lalana 2009).

In the Lesser Antilles, six amphipod species are known (Floresorchestia guadalupensis Ciavatti, 1989, Hyalella caribbeana Bousfield, 1996, Platorchestia platensis (Krøyer, 1845), Amphiatlantica sulensoni (Stebbing, 1899), Tethorchestia antillensis Bousfield, 1984 and Tethorchestia karukarae Ciavatti, 1989), all from sandy beaches, lakes and ponds and only on Guadeloupe. No terrestrial species are known to date. Moreover, there is no knowledge on the distribution of amphipods on Martinique Island, so the exploration of Pitons du Carbet carried out in 2017 and 2018 could therefore be considered as the first contribution to the description of the amphipod fauna of the island, notwithstanding the fact that these samplings were focused on soil arthropods of the tropical sub-mountain rainforest.

The present paper provides the description of a new terrestrial amphipod, attributed to the genus Cerrorchestia Lindeman, 1990 and collected above $1000 \mathrm{~m}$ of altitude in Pitons du Carbet Mountain Range. A few ecological comments about this new species and a key to the terrestrial species of the region are provided.

\section{Materials and methods}

\section{Study sites}

Amphipods were sampled in the mountain range of Pitons du Carbet on Martinique Island where they occur above $1000 \mathrm{~m}$ in small forest patches distributed around the summits and high plateaus. The vegetation has the characteristic of a cloud forest, i.e., it is subjected to high precipitation (mean annual rainfall above $6000 \mathrm{~mm}$ ), high nebulosity and epiphytic plants are very abundant. The species was found in the litter layer of Clusia mangle Rich. ex Planch. \& Triana and Schefflera attenuate (Sw.) Frodin, which are the two dominant tree species of the area. Amphipods were found at two localities - the pass between the Piton Alma and Piton Dumauzé (alt. $1045 \mathrm{~m}, 14^{\circ} 41^{\prime} 56.6^{\prime \prime} \mathrm{N}, 61^{\circ} 06^{\prime} 08.0^{\prime \prime} \mathrm{W}$ ) and on the top

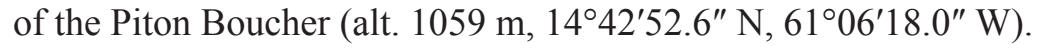

\section{Amphipod sampling}

Specimens were collected on the forest floor by means of different quantitative and non-quantitative methods (hand collection and Tullgren extraction). After separation from the remaining material, the specimens of Cerrorchestia were transferred to $96^{\circ}$ alcohol vials and dissected under a stereo microscope SZX16 $\left(\right.$ Olympus $\left.^{\odot}\right)$. Amphipod slides were prepared using Faure's media after maceration of material in lactic acid and $\mathrm{KOH}(10 \%)$ and coloration with pink lignin (Ayati et al. 2018). Digital pictures were realized with a microscope equipped with a CCD microscopy camera infinity 3-1 (Luminera $\odot$ ) and the stacking software CombineZP in order to create a composite image with an extended depth of field. Body parts were digitally drawn using a Wacom tablet and the Illustrator CC software package (AdobeTM) following the method proposed by Coleman 2003.

The total length of specimens was measured with a microscope eyepiece from the front of the head to the tip of the telson. 
PISCART C. et al., A new terrestrial amphipod species from Caribbean islands

\section{Institutional abbreviations}

MNHN = Muséum national d'histoire naturelle, Paris, France

CIRAD $=$ Centre de coopération internationale en recherche agronomique pour le développement, Lamentin, Martinique

\section{Results}

Class Malacostraca Latreille, 1802

Order Amphipoda Latreille, 1816

Family Talitridae, Raffinesque, 1815

Genus Cerrorchestia Lindeman, 1990

Cerrorchestia taboukeli sp. nov. urn:1sid:zoobank.org:act:2C82118B-19F6-49F9-90F9-F8D2708943FC

Figs 1-5, Table 1

\section{Diagnosis}

\section{Male}

Left lacinia mobilis 4-dentate; gnathopods 1 and 2 sexually dimorphic; palm of gnathopod 2 much larger than on gnathopod 1; pellucid lobes on merus, carpus and propodus of gnathopod 1 only. Pereopods 3-7 cuspidactylate. Pereopods 3-4 and telson sexually dimorphic.

\section{Female}

Gnathopod palms equal in size; pellucid lobes on merus, carpus and propodus of gnathopod 2 only. Gnathopod 1 palm subchelate, dactylus long and curved, overreaching the palmar angle.

\section{Etymology}

The epithet taboukeli refers to 'Taboukéli oüébo' in the Kalinago language, the pre-Columbian inhabitants of Martinique Island. This term means 'summit of the mountain' and refers to the extremely narrow distribution area of the species that is currently known to be restricted to peaks and high plateaus of Pitons du Carbet Mountain Range.

\section{Material examined}

\section{Holotype}

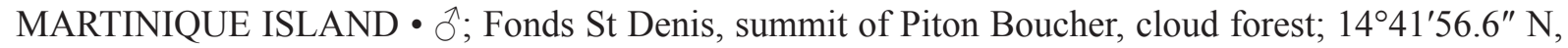
$61^{\circ} 06^{\prime} 08.0^{\prime \prime} \mathrm{W}$; $1059 \mathrm{~m}$ a.s.1.; 21 Jul. 2017; collected from leaf litter by hand and using a Tullgren extractor; MNHN-IU-2019-2276.

\section{Paratypes}

MARTINIQUE ISLAND • $5 \widehat{\partial} \widehat{\jmath}$; same collection data as for holotype; MNHN-IU-2019-2277 • 5 우; same collection data as for preceding; MNHN IU-2019-2278・2 $\widehat{\partial}, 5$ 우; same collection data as for preceding; Aug. 2018; collected from leaf litter by hand and using Tullgren extractior; CIRAD-361302-P.

\section{Other material examined}

MARTINIQUE ISLAND • ca 25 adult specimens; 2 stations, $14^{\circ} 41^{\prime} 56.6^{\prime \prime} \mathrm{N}, 61^{\circ} 06^{\prime} 08.0^{\prime \prime} \mathrm{W}$ and $14^{\circ} 42^{\prime} 52.6^{\prime \prime} \mathrm{N}, 61^{\circ} 06^{\prime} 18.0^{\prime \prime} \mathrm{W}$; Jun. 2017 and Aug. 2018; collected on forest floor by hand in the leaf litter of the Carpet Mountain. 


\section{Description}

\section{Male}

Description based on holotype male $11.3 \mathrm{~mm}$.

Body (Fig. 1A). Medium and smooth.

HeAd. Eye medium (1/3 head length), round, black. Antenna 1 (Fig. 1B) short, slightly longer than article 4 of antenna 2, flagellum with up to 5 short articles, sparsely setose with robust setae. Antenna 2 (Fig. 1C) less than half body length; peduncular articles slender, article $51.3 \times$ longer than article 4; flagellum longer than peduncles with up to 20 articles with robust setae. Upper lip (Fig. 2A) wide, apex rounded and setose. Lower lip (Fig. 2C) without inner lobe; outer lobe very setose with sub-rectangular apical margin. Left mandible (Fig. 2E) incisor 6-dentate, lacinia mobilis 4-dentate, molar triturative,

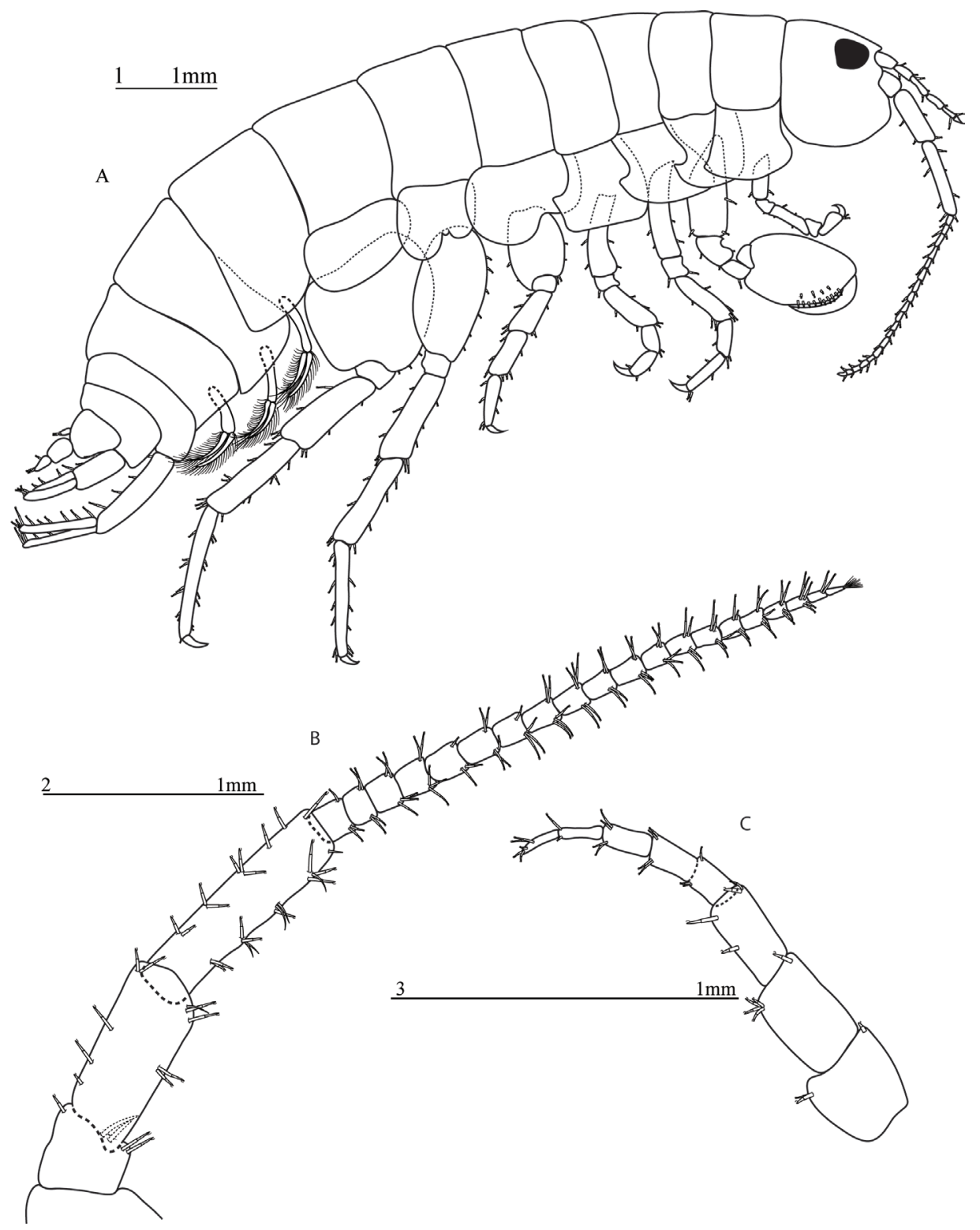

Fig. 1. Cerrorchestia taboukeli sp. nov., holotype, $\widehat{\partial}, 11.3 \mathrm{~mm}$, MNHN-IU-2019-2276. A. Habitus (scale 1). B. Second antenna (scale 2). C. First antenna (scale 3). 
strong. Maxilla 1 (Fig. 2F): inner plate rod-shaped with two terminal robust pappose setae; outer plate with eight terminal serrate setae, palp absent. Maxilla 2 (Fig. 2D): inner plate sub-equal to outer plate in length with 1 large and 1 medium secondary subapical pappose setae; outer plate with 2 setae on outer margin and a row of terminal robust setae. Maxilliped (Fig. 2B): inner plate well developed, $4 \times$ longer than wide, with apical pappose setae and 3 spatule-like spine teeth, inner lateral margin bordered by 4 robust pappose setae; outer plate long, exceeding palp article 1 with apical pappose setae; palp article 2 about as long as wide, inner lobe wide; palp article 3 slightly longer than wide, shorter than palp article 2; palp article 4 minute, dome-shaped, masked by distal setae and setae of palp article 3 .
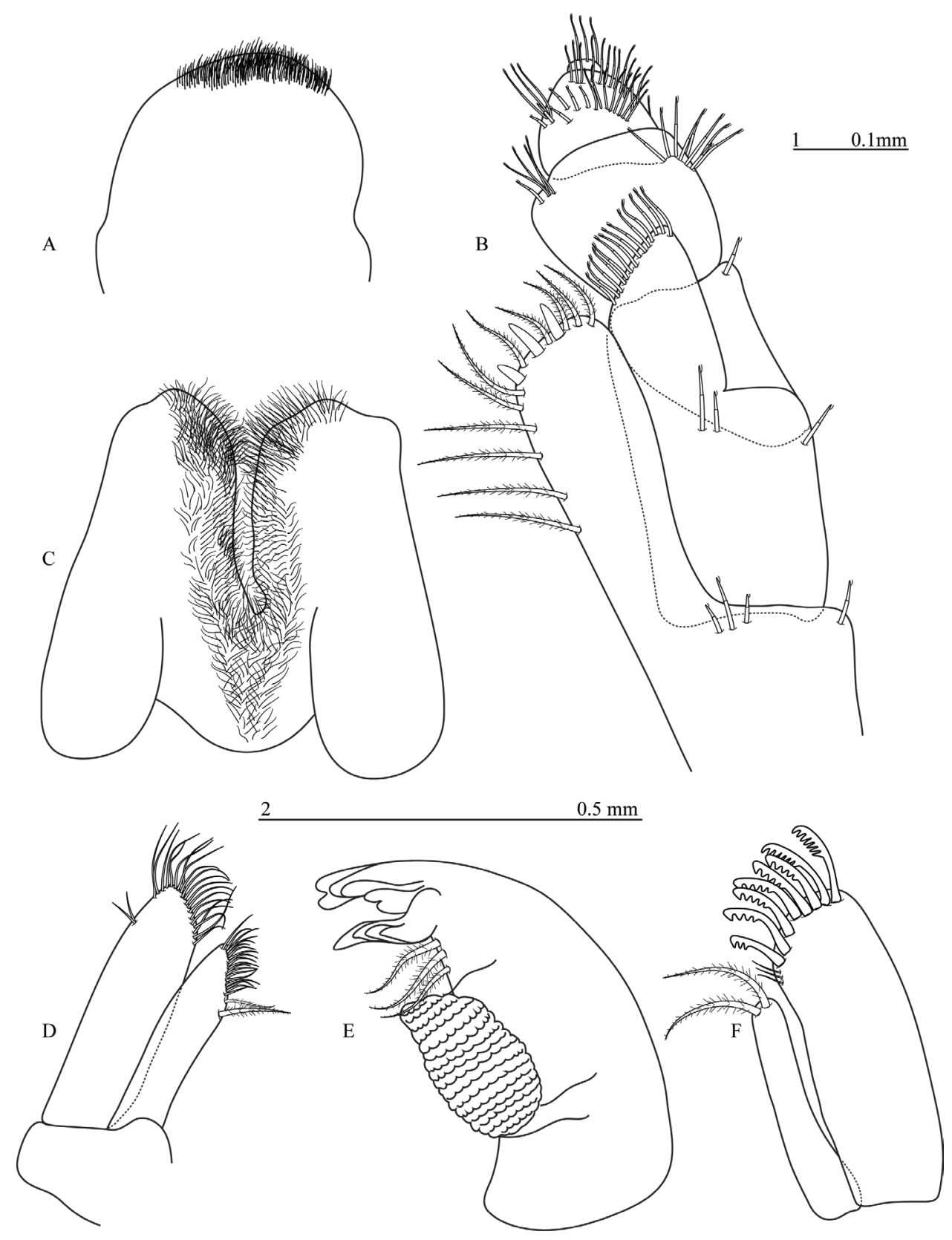

Fig. 2. Cerrorchestia taboukeli sp. nov., holotype, ${ }^{\lambda}, 11.3 \mathrm{~mm}$, MNHN-IU-2019-2276. A. Upper lip (scale 2). B. Maxilliped (scale 1). C. Lower lip (scale 2). D. Maxilla 2 (scale 2). E. Left mandible (scale 2). F. Maxilla 1 (scale 2). 
Pereon. Gnathopod 1 (Fig. 3A) sexually dimorphic, subchelate; basis slightly expanded posterodistally, 2 proximal facial setae, 3 setae on posterior margin; pellucid lobes on merus, carpus and propodus; carpus longer than propodus, triangular, well developed with posterior carpal lobe posterior margin with long setae; propodus of 'hammer' type, expanding distally, inner face with many seta of various length, anterior margin with 3 groups of 1-3 setae and 4 fine setae distally, palm transverse fringed with 6-8 long setae and 5-6 tiny facial setae proximally; dactyl posterior margin with setae only. Gnathopod 2 (Fig. 3B) much larger than gnathopod 1, subchelate, sexually dimorphic; coxa subrectangular slightly longer than wide with a rounded ventral margin; basis expanded posterodistally without setae on anterior margin and 4 small setae on posterior margin; ischium and merus unarmed; carpus triangular, very small and unarmed; propodus ovate, two times as long as wide, inner face with 6-7 small setae, palm transverse fringed with many apical setae of various length; dactylus very long, overreaching the palmar angle. Pereopod 3-7 cuspidactylate. Pereopods 3-4 (Fig. 4A-B) alike; subequal in length; coxae subquadrate with posterior lobes; merus not expanded, $1.5 \times$ larger and longer than carpus; pereopod 4 propodus longer than carpus, dactylus short with anterodistal denticular patch. Pereopod 5 (Fig. 4E) coxa bilobed; basis ovate with deep posterodistal lobe reaching distal end of ischium, anterior and posterior margin fringed with setae; merus expanded and equal in length to carpus; propodus longer than merus and carpus; dactylus short. Pereopods 6-7 (Fig. 4F-G) alike, subequal in length, meri and carpi similar in length and propodi longer; dactylus very thin and relatively long. Pereopod 6 coxa bilobed; basis ovate. Pereopod 7 coxa ovate; basis almost round.

PLEON. Epimeron 1 widely subtriangular, lacking posterior tooth, without spine on posterior margin. Epimera 2 and 3 subquadrates, posterior distal angles somewhat produced but lacking distinct tooth and without setae of posterior margin (Fig. 5G). Pleopods 1-3 (Fig. 5H-J) well developed, pleopods 1 and 2
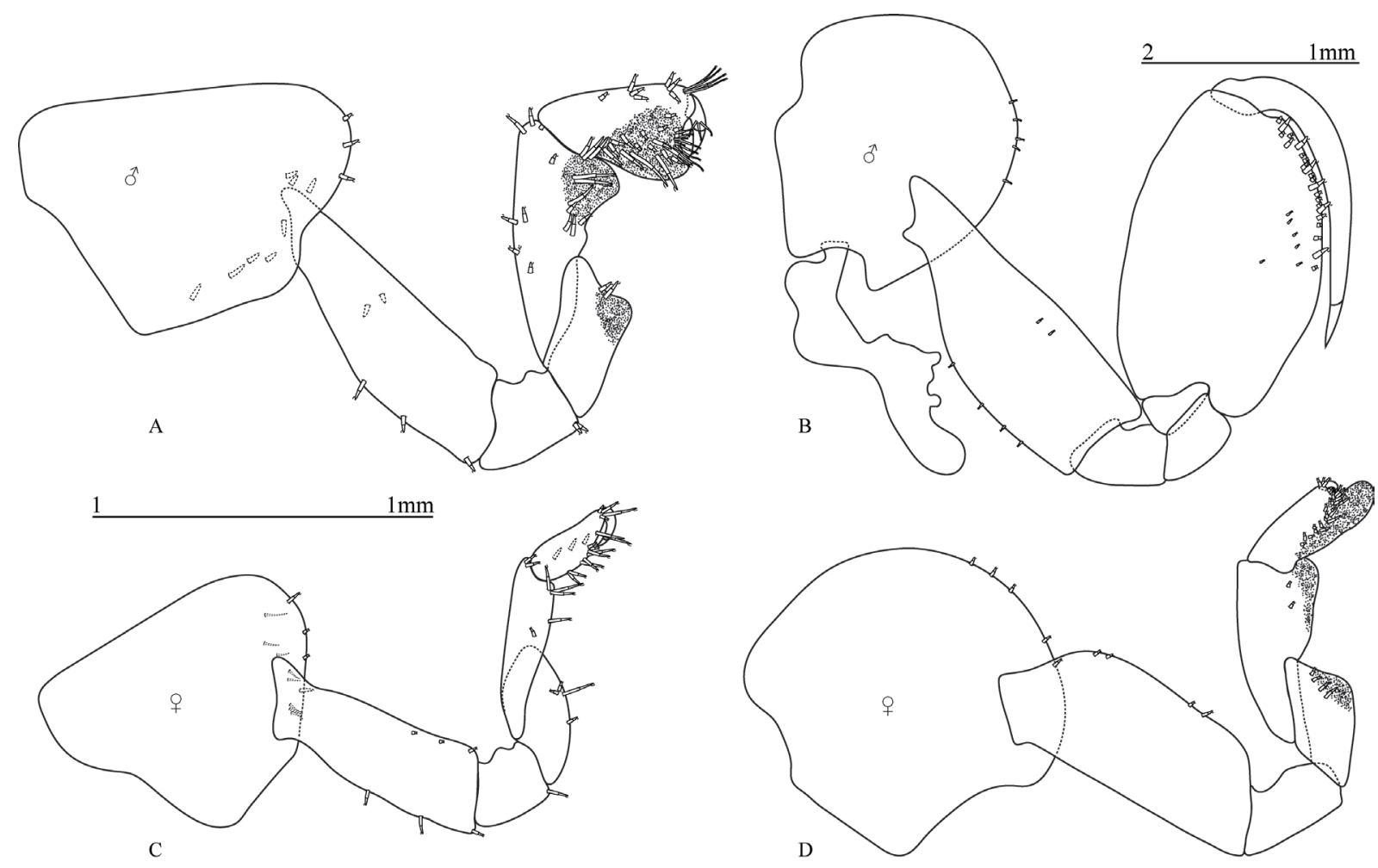

Fig. 3. Cerrorchestia taboukeli sp. nov. A-B. Holotype, Ô, $11.3 \mathrm{~mm}$, MNHN-IU-2019-2276. C-D. Paratype,, , 9.6 mm, MNHN-IU-2019-2278. A. Gnathopod 1 (scale 1). B. Gnathopod 2 (scale 2). C. Gnathopod 1 (scale 1). D. Gnathopod 2 (scale 1). 
longer than pleopod 3, peduncles well developed 5-6 $\times$ longer than wide, $1 \sim 3$ coupling spines; flagellum biramous, subequal in length; pleopod 1 inner and outer rami with 8 and 10 articles, respectively; pleopod 2 inner ramus with 7 articles, outer with 10 articles; pleopod 3 inner and outer rami very short with 8 articles. Uropod 1 (Fig. 5A) longest; peduncle slender $5 \times$ as long as wide with one row of 5 setae and a strong interramal seta; inner ramus with 4 dorsal marginal setae and few apical robust setae; outer ramus without marginal setae. Uropod 2 wider; peduncle $2 \times$ as long as wide with 3 dorsal marginal

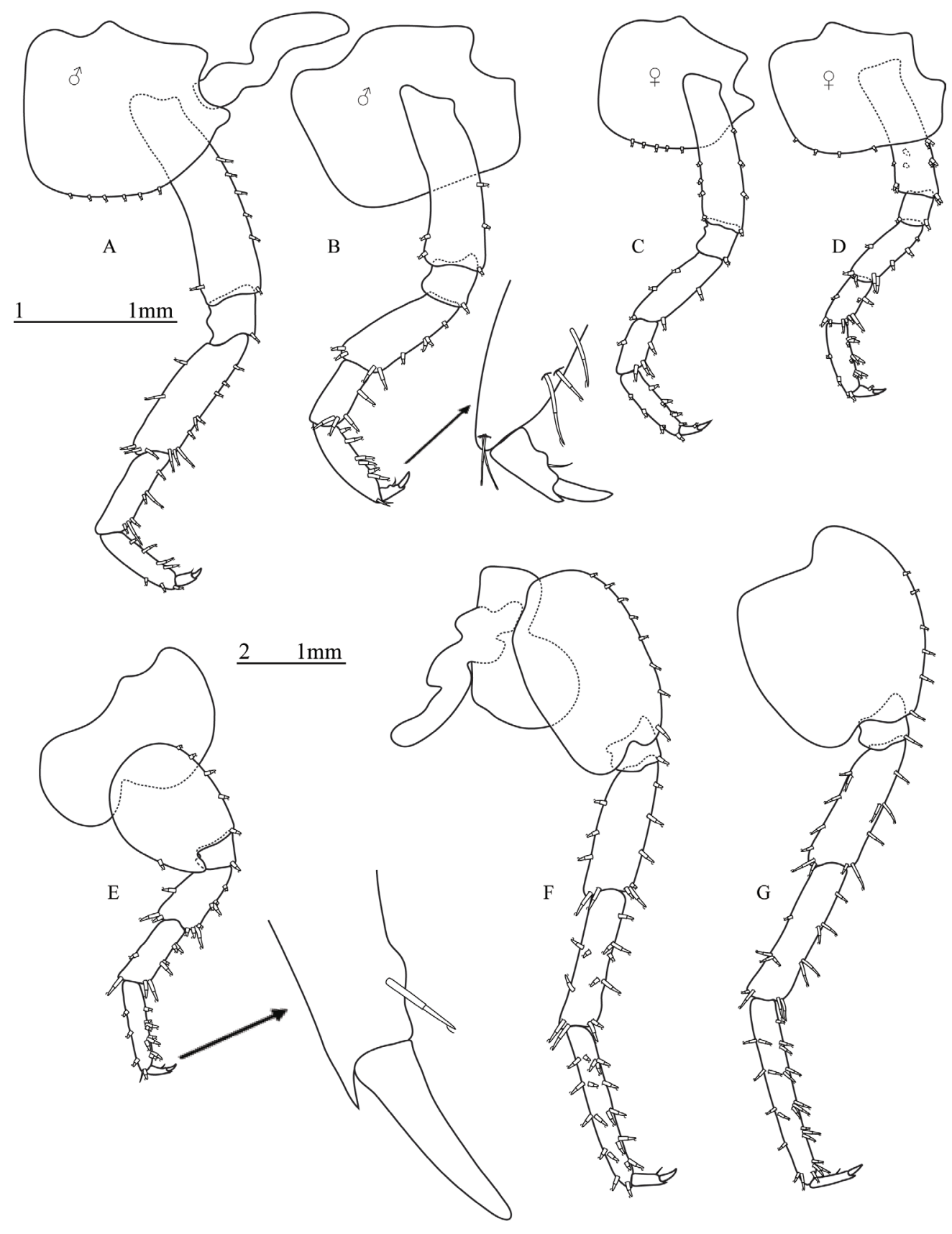

Fig. 4. Cerrorchestia taboukeli sp. nov. A-B, E-G. Holotype, Ô, 11.3 mm, MNHN-IU-2019-2276. C-D. Paratype, o, 9.6 mm, MNHN-IU-2019-2278. A. Pereopod 3 (scale 1). B. Pereopod 4 (scale 1). C. Pereopod 3 (scale 1). D. Pereopod 4 (scale 1). E. Pereopod 5 (scale 2). F. Pereopod 6 (scale 2). G. Pereopod 7 (scale 2). 
setae, 4 marginal or sub-marginal ventral setae smaller, and one apical robust setae; inner ramus with 3 dorsal marginal setae; outer ramus with 5 marginal setae. Uropod 3 peduncle with 2 apical setae dorsally and several very small facial setae, uniramus, ramus slightly arcuate subequal to peduncle in length, not fused to peduncle with 1 dorsal marginal seta and 4 apical setae. Telson (Fig. 5E) weakly longer than wide, weakly cleft, each lobe with $2-3$ marginal and 2-3 apical setae.

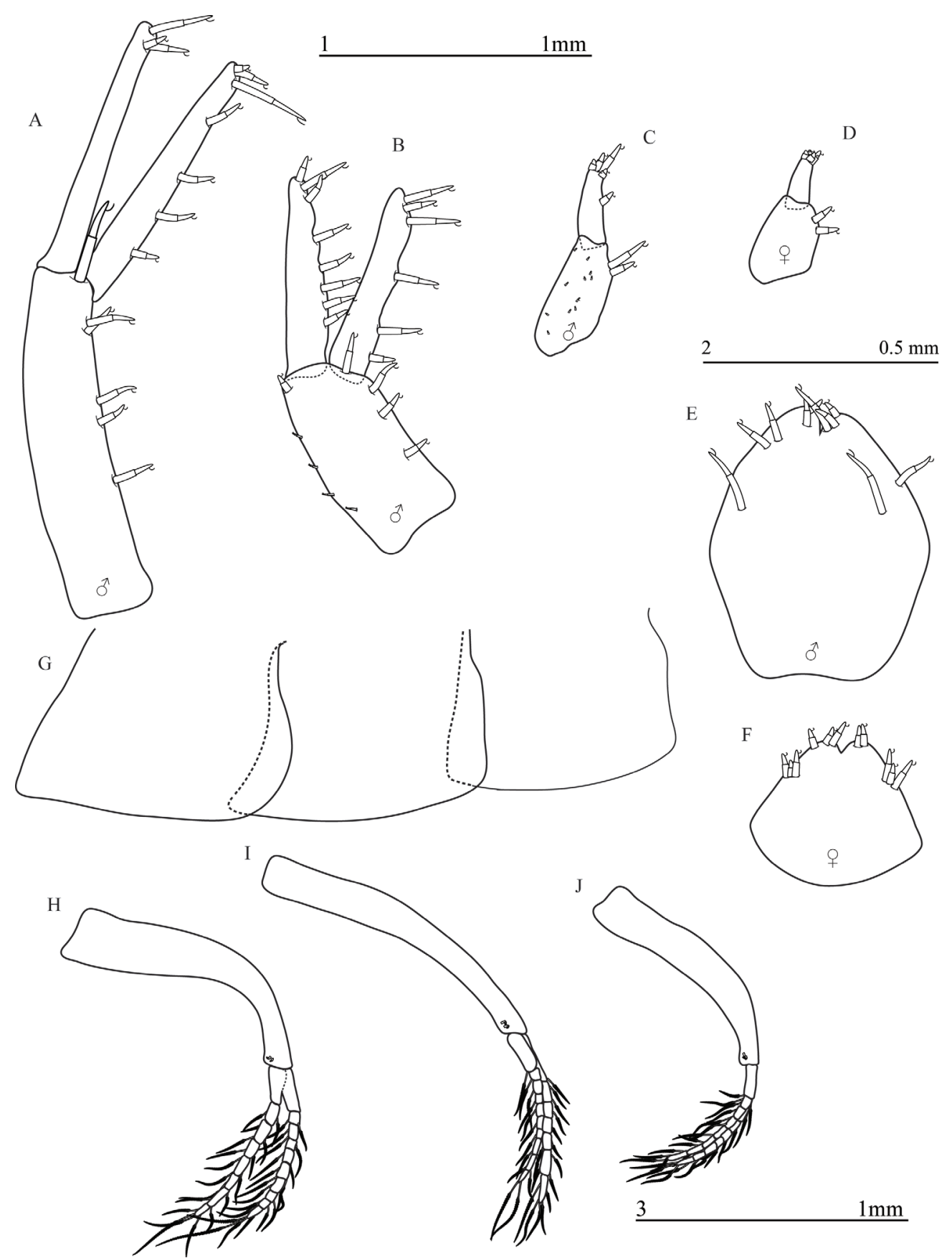

Fig. 5. Cerrorchestia taboukeli sp. nov. A-C, E, G-I. Holotype, đ̃, 11.3 mm, MNHN-IU-2019-2276. D, F. Paratype,, , 9.6 mm, MNHN-IU-2019-2278. A. Uropod 1 (scale 1). B. Uropod 2 (scale 1). C. Uropod 3 (scale 1). D. Uropod 3 (scale 1). E. Telson lobes (scale 2). F. Telson lobes (scale 2). G. Epimera 1-3 (scale 1). H. Pleopod 1 (scale 3). I. Pleopod 2 (scale 3). J. Pleopod 3 (scale 3). 


\section{Female}

Description based on paratype female $9.6 \mathrm{~mm}$.

HEAD. Antenna 1 and 2 similar to those of male.

Pereon. Gnathopod 1 (Fig. 3C) equal in size to gnathopod 2 (Fig. 3D), subchelate; coxa triangular, slightly longer than wide, posterior margin excavated; basis not expanded; merus trapezoid; carpus slender, well developed, longer than merus and propodus; propodus slender, palm with long setae along posterior margin and a line of three setae on outer face; dactylus long and curved, overreaching the palmar angle. Gnathopod 2 (Fig. 3D) weakly chelate; coxa subrectangular, slightly longer than wide with a rounded ventral margin; basis expanded posteriorly with 4 small setae on posterior margin; pellucid lobes on merus, carpus and propodus; merus trapezoid with 2 setae near the pellucid lobe, carpus triangular, enlarged at it distal end and armed with setae of various length; propodus triangular, $2 \times$ as long as wide, inner face with many setae of various length, pellucid lobe well developed, extending beyond palm, palm transverse fringed with many apical setae of various length; dactylus short, reaching to half of palm. Pereopod 3-4 (Fig. 4C-D) not modified, sexually dimorphic. Pereopod 3 ischium modified; carpus short, shorter than merus and propodus, merus, carpus and propodus longer on pereopod 3 than on pereopod 4; pereopod 4 merus as wide as carpus and propodus. Pereopod 5 basis subrectangular without posterodistal lobe.

Pleon. Uropod 3 (Fig. 5D) peduncle without facial setae; ramus without marginal setae. Telson (Fig. 5F) weakly cleft with one group of 3 marginal setae on each lobe and 2-3 apical setae.

\section{Differential diagnosis}

The genus Cerrorchestia currently contains only one species: C. hyloraina Lindeman, 1990. Cerrorchestia taboukeli sp. nov. differs from C. hyloraina in several characteristics: maxilliped inner plate bordered by 4 robust pappose setae; number of setae on posterior margin of basis of gnathopod 1; gnathopod 2 carpus triangular, very small, palm longer than wide; pereopods 3-4 sexually dimorphic; pereopod 4 with a denticulate patch; pereopod 5 base ovate with deep posterodistal lobe reaching distal end of ischium; pereopod 6 coxa bilobed without carina; pleopod 3 peduncle with 8 articles; uropod 1 peduncle with 1 row of 5 setae; uropod 3 ramus with 1 dorsal marginal seta; telson sexually dimorphic, telson of males wider than long, cleft until half of length, each lobe with 2 or 3 marginal and 2 apical setae, telson of female weakly cleft with one group of 3 marginal setae on each lobe and 2-3 apical setae.

\section{Identification key to known species of terrestrial amphipods from Central America and Caribbean Islands (updated from Lindeman 1990)}

1. Gnathopod 2 sexually dimorphic, gnathopod 2 longer than gnathopod 1 2

- Gnathopod 2 not sexually dimorphic, gnathopods 1 and 2 similar in size

2. Pleopods 1-3 vestigial; uropod 1 without an interramal seta ....Cariborchestia xerophila Smith, 1998

- Pleopods 1-3 multi-articulated, normally developed; uropod 1 with an interramal seta ................ 3

3. Gnathopod 2 carpus longer than wide, palm almost round, pereopod 3 dactylus without denticulate patch, pereopod 5 basis ovate without posterodistal lobe, pleopod 3 with up to 6 articles

Cerrorchestia hyloraina Lindeman, 1990

- Gnathopod 2 carpus short, palm longer than wide, pereopod 4 dactylus with a denticulate patch, pereopod 5 basis ovate with a deep posterodistal lobe reaching the distal end of the ischium, pleopod 3 ramus with more than 6 articles

Cerrorchestia taboukeli sp. nov. 
4. Pleopod 3 ramus vestigial; uropod 1 interramal seta with hooked spade-like tip, uropod 2 outer ramus lacking dorsal setae

- Pleopod 3 ramus multi-articulated; uropod 1 interramal seta simple, uropod 2 outer ramus with dorsal setae

5. Uropod 1 peduncle with simple setae, pleopod 3 peduncle $0.4 \times$ as long as uropod 2 peduncle, antenna 2 flagellum as long as or smaller than the peduncle, maximum size of adults $7 \mathrm{~mm}$

Talitroides alluaudi (Chevreux, 1896)

- Uropod 1 peduncle with bifid setae, pleopod 3 peduncle $>0.6 \times$ as long as uropod 2 peduncle, antenna 2 flagellum as long as or smaller than the peduncle, maximum size of adults $13 \mathrm{~mm}$

Talitroides topitotum (Burt, 1934)

6. Uropod 1 outer ramus without setae; pleopod rami equal in length or shorter than the peduncle ... 7

- Uropod 1 outer ramus with setae; pleopod rami longer than the peduncle

7. Pleopod rami $1 / 3$ of peduncle, telson quadrangular without dorsal setae uropod 3 base of peduncle narrow Caribitroides genaroi Ortiz \& Lalana, 2009

- Pleopod rami equal in length to peduncle, telson triangular with dorsal setae, uropod 3 base of peduncle wide

8. Pleopod 3 comparable in length to pleopod 2, rami of each pleopod approximately equal in length; maxilliped inner plate sparsely setose, with apical spine teeth

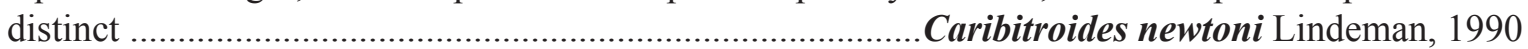

- Pleopod 3 comparable in length to pleopod 2, rami of each pleopod unequal in length; maxilliped inner plate setose, with apical spine teeth distinct

9. Pleopod rami distinctly unequal, outer shorter; telson lobes with 1 apical

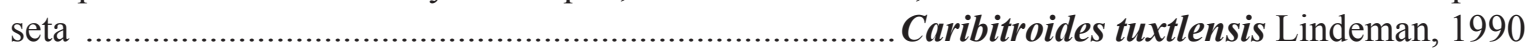

- Pleopod 1-2 rami distinctly unequal, inner rami shorter, pleopod 3 rami subequal; telson lobes with 2-3 apical setae Caribitroides jamaicensis Bousfield, 1984

10. Epimeron 3 quadrate; coxal plate 6 without tiny spines anterior to carina; maxilliped palp article 2 wide (medially much wider than article 3 ) .Mexitroides chiapensis (Lindeman, 1990)

- Epimeron 3 with distinctive curved ventral margin; coxal plate 6 with tiny spines anterior and posterior to carina; maxilliped palp article 2 narrow (medially little wider than article 3)

Mexitroides pecki (Lindeman, 1990)

\section{Ecology and distribution}

Cerrorchestia taboukeli sp. nov. was found in very wet conditions of the Pitons du Carbet Mountain Range (annual precipitation higher than $6000 \mathrm{~mm}$ per year) always at an altitude higher than $1000 \mathrm{~m}$. At this altitude, the cloud forest is sparse, alternating with mountain grassland (Fig. 6A). It is worth noting that $C$. taboukeli sp. nov. was found only under tree patches in a shaded environment where leaves of Clusia mangle and Schefflera attenuate create a thick litter layer on the soil. During daylight, the animals rest almost motionless under the leaf litter unless disturbed, in which cases they actively jump in search for shelter. Live C. taboukeli sp. nov. are very dark brownish red (Fig. 6A). Using a quadrat of $25 \times$ $25 \mathrm{~cm}$, the population density was estimated to be, on average, $196 \pm 112 \mathrm{ind} / \mathrm{m}^{2}(\mathrm{n}=9)$. The sex ratio of adults was biased toward females, and juveniles represented more than $75 \%$ of the population during the sampling period. The other species of the genus, C. hyloraina, is known from Panama to Costa Rica in similar environmental conditions (Lindeman 1990). The species live in leaf litter of cloud forest with an andosol developed on volcanic rocks (andesite). The main soil characteristics are given in Table 1. 
Table 1. Soil characteristics of the type locality.

\begin{tabular}{|l|l|}
\hline Nitrogen (\%) & 0.99 \\
\hline Carbon $(\%)$ & 17.66 \\
\hline Phosphorus $\left(\mathrm{mg}^{\mathrm{kg}} \mathrm{kg}^{-1}\right)$ & 10.35 \\
\hline Magnesium $\left(\mathrm{cmol} . \mathrm{kg}^{-1}\right)$ & 1.87 \\
\hline Calcium $\left(\mathrm{cmol} . \mathrm{kg}^{-1}\right)$ & 3.43 \\
\hline Potassium $\left(\mathrm{cmol} . \mathrm{kg}^{-1}\right)$ & 0.39 \\
\hline $\mathrm{pH}($ water$)$ & 4.56 \\
\hline
\end{tabular}

To date, the distribution of $C$. taboukeli sp. nov. is restricted to only two localities in the Pitons du Carbet Mountain Range (Martinique Island). Prospecting the three other islands of Lesser Antilles having large mountain ranges covered by tropical rainforest (i.e., Guadeloupe, Dominica and St Lucia) could elucidate whether other species of forest-hopper talitrids inhabit the Lesser Antilles and also whether C. taboukeli sp. nov. is strictly endemic to Martinique.

\section{Discussion}

Classification of the members within the highly diverse family Talitridae is very complex with 116 genera for only 358 species (WORMS 2019), among which 68 have been described over the last 20 years (Lowry \& Myers 2019). Bousfield (1984) proposed to organize Talitridae in four systematic-ecological groups according to their ecological preferences. Those groups are polyphyletic and overlapping, but are pragmatically useful (Bousfield 1984). The first group harbors palustrine semi-aquatic species living in estuarine and some freshwater habitats of tropical and antipodean continental areas. The second group pools together the semi-terrestrial and terrestrial (but non-substrate-modifying) beach flea species living in supralittoral and coastal rain forests of tropical to boreal marine coastlines. The third group harbors specialized (substrate-modifying) semi-terrestrial, supralittoral sand hoppers living on sandy beaches of tropical and temperate marine shores. Finally, the fourth group contains specialized terrestrial (but seldom substrate-modifying) land hoppers, living in coastal continental and high-island angiosperm rain forests, mainly of tropical Indo-Pacific and antipodean temperate regions. In their recent revision of Talitridae, Lowry \& Myers (2019) proposed to divide the terrestrial land-hopper group into six groups to
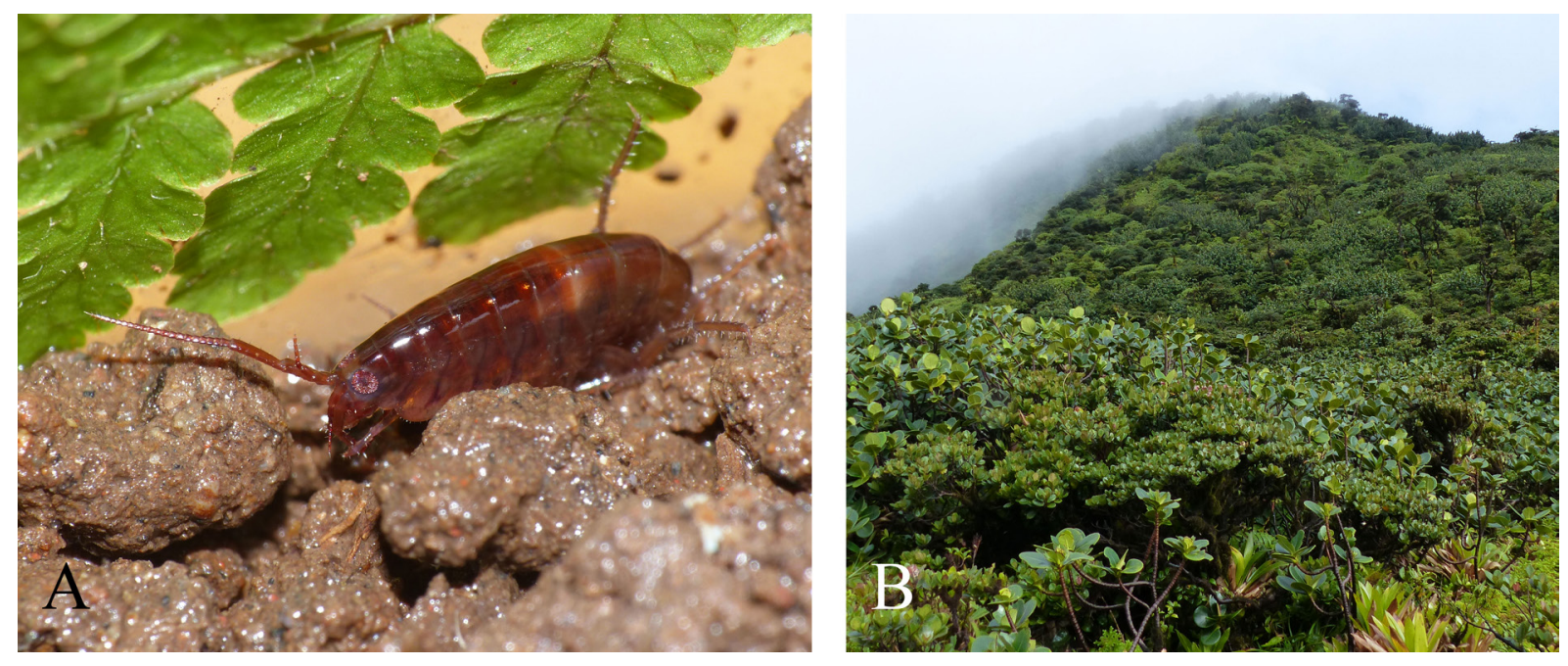

Fig. 6. Cerrorchestia taboukeli sp. nov. A. Live. B. Natural environment. 
account for the wide variety of ecotypes occupied by terrestrial talitrids. Cerrorchestia taboukeli sp. nov. described in this study confirms the characteristic terrestrial specialization of the genus Cerrorchestia (Lindeman 1990), considered as one of the 75 genera with terrestrial species belonging to the foresthoppers (Lowry \& Myers 2019).

Cerrorchestia taboukeli sp. nov. is the first forest-hopper in a Caribbean Island discovered from a genus other than Caribitroides (C. jamaicensis Bousfield, 1984 in Jamaica and C. genaroi Ortiz \& Lalana, 2009 in Hispaniola). All other forest-hopper species found in the region are restricted to Mexico (Caribitroides newtoni, Caribitroides tuxtlensis, Mexitroides chiapensi and Mexitroides pecki), Costa Rica and Panama (C. hyloraina) (Lindeman 1990).

In a morphological study, Lindeman (1991) discovered that the genera Caribitroides and Cerrorchestia from Central America and Jamaica evolved from a palustrine ancestor close to the Chelorchestia. Smith (1998) rejected this hypothesis by describing the genus Cariborchestia from a small island of Puerto Rico, which differs substantially from both Caribitroides and Cerrorchestia, and proposed another hypothesis with a proto-antillean beach flea close to Tethorchesta (Bousfield, 1984) as the ancestor of Cariborchestia. In accordance with Smith's hypothesis, Bousfield \& Poinard (1995) described a fossil amphipod belonging to the genus Tethorchesta. Moreover, Lowry \& Myers (2019) confirm that the mascupod (i.e., enlarged male gnathopod 2) is an important morphological trait that tends to confirm that Cerrorchestia (with mascupod) is probably not closely related neither to Cariborchestia nor to Mexitroides, both genera having femipods (gnathopod 2 not enlarged). Moreover, a vicariant event is not favored as the explanation for most patterns of biogeographical distribution in the Lesser Antilles because most of islands were under water until the end of the Oligocene (23 Ma). Indeed, a protoAntillean vicariant event cannot be invoked to explain the presence of many plant species from South America (Buck 1990). Consequently, the vicariance hypothesis is apparently not a good explanation of the presence of Cerrorchestia in both Panama and on the Lesser Antilles. The presence of the genus Cerrorchestia on the Lesser Antilles and in Panama is more congruent with the mid-Cenozoic Greater Antilles Aves Ridge land bridge (GAARlandia) hypothesis at a time when ocean levels were lower and land masses were closer to each other (Iturralde-Vinent \& MacPhee 1999). The most likely explanation is a colonization of the Lesser Antilles by a South American ancestor at the Eo-Oligocene boundary ( $34 \mathrm{Ma}$ ), followed by the colonization of Panama when the Panamanian Isthmus arose between 2.3 and 9.0 Ma ago (Iturralde-Vinent 2006). Unfortunately, the knowledge on talitrids of this region remains very scarce and does not allow us to formulate sustainable hypotheses concerning the colonization of Caribbean Islands by amphipods. Further research including phylogeographical studies may help us to disentangle the evolutionary history of Talitridae in the region.

\section{Acknowledgements}

Field work was carried out within the project on the invertebrate fauna diversity of the Integral Biological Reserve of the Pitons du Carbet (Martinique Island), a project led by the Institut Caribéen pour la Nature et la Culture (ICNC).

\section{References}

Ayati K., Dhaouadi S., Mahmoudi E. \& Piscart C. 2018. Two new species of gammarid amphipods from Tunisian fresh waters (Amphipoda, Gammaridae). Crustaceana 91 (11): 1327-1345. https://doi.org/10.1163/15685403-00003837

Bousfield E.L. 1984. Recent advances in the systematics and biogeography of landhoppers (Amphipoda: Talitridae) of the Indo-Pacific Region. In: Radovsky F.J., Raven P.H. \& Somer S.H. (eds) Biogeography of the Tropical Pacific. Proceedings of the Symposium: 171-205. Bishop Museum Special Publication, Honolulu. 
PISCART C. et al., A new terrestrial amphipod species from Caribbean islands

BousfieldE.L.\&PoinarG.O.1995.Newterrestrial amphipod fromTertiary amberdepositsofthe Dominican Republic. Journal of Crustacean Biology 15 (4): 746-755. https://www.jstor.org/stable/1548823

Buck W.R. 1990. Biogeography of the Greater Antillean mosses. Tropical Bryology 2: 35-48. http://doi.org/10.11646/bde.2.1.3

Ciavatti G. 1989. Les Talitres (Crustacea. Amphipoda) des plages de la Guadeloupe. Description de deux espèces nouvelles. Annales de l'Institut océanographique 65 (2): 127-146.

Coleman C.O. 2003. "Digital inking": how to make perfect line drawings on computers. Organisms, Diversity \& Evolution 3 (4): 303-304. https://doi.org/10.1078/1439-6092-00081

Iturralde-Vinent M.A. 2006. Meso-Cenozoic Caribbean paleogeography: implications for the historical biogeography of the region. International Geology Review 48: 791-827.

https://doi.org/10.2747/0020-6814.48.9.791

Iturralde-Vinent M.A. \& MacPhee R.D.E. 1999. Paleogeography of the Caribbean region: implications for Cenozoic biogeography. Bulletin of the American Museum of Natural History 238: 1-95.

Lindeman D. 1990. New terrestrial amphipods (Crustacea: Amphipoda; Talitridae) from México and Central America. Canadian Journal of Zoology 68 (11): 2323-2337. https://doi.org/10.1139/z90-324

Lindeman D. 1991. Natural history of the terrestrial amphipod Cerrorchestia hyloraina Lindeman (Crustacea: Amphipoda; Talitridae) in a Costa Rican cloud forest. Journal of Natural History 25 (3): 623-638. https://doi.org/10.1080/00222939100770391

Lowry J.K. \& Myers A.A. 2019. New genera of Talitridae in the revised superfamily Talitroidea Bulycheva 1957 (Crustacea, Amphipoda, Senticaudata). Zootaxa 4553 (1): 1-100.

https://doi.org/10.11646/zootaxa.4553.1.1

Ortiz M. \& Lalana R. 2009. A new terrestrial amphipod (Crustacea, Amphipoda, Talitridae) from the Dominican Republic. Solenodon 8: 25-32.

Smith D.G. 1998. A new genus and species of terrestrial amphipod from Isla Mona in the Caribbean Sea (Crustacea, Amphipoda, Talitridae). Spixiana 21 (2): 179186. https://www.biodiversitylibrary.org/page/28199525\#page/189

Smith D.G. \& Heard R.W. 2001. A new species of Chelorchestia (Amphipoda: Talitridae) from Southwest Florida, with comments on other species within the genus. Journal of Crustacean Biology 21 (4): 1031-1041. https://doi.org/10.1163/20021975-99990195

Wildish D.J. \& LeCroy S.E. 2014. Mexorchestia: a new genus of talitrid amphipod (Crustacea, Amphipoda, Talitridae) from the Gulf of Mexico and Caribbean Sea, with the description of a new species and two new subspecies. Zootaxa 3856 (4): 555-577.

Manuscript received: 15 July 2019

Manuscript accepted: 3 October 2019

Published on: 12 December 2019

Topic editor: Rudy Jocqué

Desk editor: Eva-Maria Levermann

Printed versions of all papers are also deposited in the libraries of the institutes that are members of the EJT consortium: Muséum national d'histoire naturelle, Paris, France; Meise Botanic Garden, Belgium; Royal Museum for Central Africa, Tervuren, Belgium; Royal Belgian Institute of Natural 
Sciences, Brussels, Belgium; Natural History Museum of Denmark, Copenhagen, Denmark; Naturalis Biodiversity Center, Leiden, the Netherlands; Museo Nacional de Ciencias Naturales-CSIC, Madrid, Spain; Real Jardín Botánico de Madrid CSIC, Spain; Zoological Research Museum Alexander Koenig, Bonn, Germany; National Museum, Prague, Czech Republic. 